\title{
Perspectives of Women during Reproductive Years for Cervical Cancer Scans and Influencing Factors
}

\author{
Gokce Banu Acar ${ }^{1}$, Gul Pinar ${ }^{2 *}$
}

\begin{abstract}
Background: This descriptive study was performed in order to assess health perspectives of women, who applied to Yildirim Beyazit University Ataturk Education and Research Hospital, Outpatient Clinic of Obstetrics and Gynecology for cervical cancer scans and were in the reproductive years. Factors influencing their perspectives were also assessed. Materials and Methods: In this study, a simple random sampling formula was adopted to calculate the volume (300) of the targeted sample. Results of the research were obtained through individual diagnosis form and cervical cancer and the Pap smear test health belief model scale (HBMS). Results: It was found that $75.0 \%$ of the women heard of the Pap smear test before, and $48.7 \%$ had undertaken one. Some 51.4\% of the women who had Pap smear test expressed that they had the test at irregular periods. Most of the women stated that they heard about the smear test from the health staff $(51.7 \%)$. Lack of any health complaints $\mathbf{2 8 . 3 \%}$ ) and not having adequate information about the test $\mathbf{2 1 . 0 \%}$ ) were among the reasons for not undergoing a Pap smear test. It was found that lower dimension average scores of the women obtained from the cervical cancer and Pap smear test HBMS varied from 7.7 \pm 2.3 to 33.5 \pm 9.3 . When the lower dimension average scores of women from the HBMS were examined, the perception of usefulness was high but the susceptibility and health motivations were low. Conclusions: In this study, it was determined that the awareness of women about cervical cancer and the Pap smear test was insufficient, and susceptibility and motivation perception towards having a Pap smear test were low.
\end{abstract}

Keywords: Risk factors-reproductive period - cervical cancer -health perspectives - health belief - Turkish women

Asian Pac J Cancer Prev, 16 (16), 7171-7178

\section{Introduction}

Cancer is a group of diseases characterized by uncontrolled cell reproduction as a result of genetic changes (WHO, 2014). In spite of the great development in medicine; cancer, which is as old as humanity, is one of the serious chronic diseases that influences deeply all of the steps in individual's life cycle (Saegrov et al., 2004; Reis et al., 2010). According to the estimations of "American Cancer Society" (ACS) approximately 1.665.540 new cancer cases will occur in America in 2014; WHO predicts that in 2030, 20 million new cancer cases will occur and there will be 12 million cancer related deaths (ACS, 2014; WHO, 2014).

Therefore cervical malignancies within gynecologic cancers, which have scanning programs, are preventable, and these are also an important reason of death in developing and undeveloped countries (Mc Farland, 2003; Guner and Taskiran, 2007). The mean cancer diagnosing age is 52 , and it peaks within the ages of 35-39 and 6064 . The incidence of the disease changes according to the areas, and while Middle East incidence is 4.8 over 100.000 , it is 44.3 over 100.000 in East Africa (Jemal et al., 2002). Cervical cancer is the second most observed gynecologic cancer for women in reproductive period (age 15-45), and 500.000 new case is seen each year (Parkin et al., 2005). $75 \%$ of the cases are observed in less developed countries and there is a twenty times difference between the countries with lowest incidence and the highest one. For example, while a woman's lifetime risk of cervical cancer in England is 1/116, it is $1 / 26$ in Africa (Ozan, 2005).

Although it is curable in case of early diagnosis, if precautions are not provided urgently, it is expected that the deaths will increase by $25 \%$ in the next decade (Nazlican et al., 2010). Cervical cancer is also a serious public health problem in this country. According to the data provided by the Ministry of Health the incidence was 4.8 over 100,000 in 2006, and it decreased to 4.4 in 2008. However, according to Health Statistics Annual (2010) there is an important increase in the number of precancerous lesions in cervix.

There are many behaviors decreasing cervix cancer risk, nevertheless none of the actions are as effective as having Pap smear test (Akyuz et al., 2006). Because cervix is an easily accessible organ, owing to Papanicolau (Pap) 
smear test, cancers in this organ could be diagnosed early, and the prognosis recovers significantly (Nazlican et al., 2010; Gumus and Cam, 2011). In developed countries, invasive cervical cancer ratio has been decreased by using Pap smear scan test for the last 50 years. Pap smear test is one of the cheap, easily applicable, and effective scanning methods which can detect any cellular change that could be cervical cancer onset (Akyuz et al., 2006; Gumus and Cam, 2011).

In spite of scanning programs, the ratio of women's cervical cancer scan involvement is not sufficient in many countries. The studies about this issue show that socio-demographic and cultural features, socioeconomic conditions, health perspectives, the knowledge about cervical cancer and Pap smear test affect the women's Pap smear test involving behaviors (Basen-Engquist et al., 2003; Kanbur and Capik., 2011). Based on this point of view, this study will enable women to take scan program by determining their health perspectives about cervical cancer scanning.

\section{Materials and Methods}

\section{Research method}

This study descriptive study was performed to assess health perspectives of women in the reproductive period for the cervical cancer scanning and the factors influencing their perspectives.

\section{Date and place of the study}

The data of the study was collected between May 1 and June 1, 2013 at Yildirim Beyazit University Ataturk Education and Research Hospital, Outpatient Clinic of Obstetrics and Gynecology in Ankara.

\section{Population of the study and sampling}

The population was composed of the women who applied to Yildirim Beyazit University Ataturk Education and Research Hospital, Outpatient Clinic of Obstetrics and Gynecology within last 1 year $(\mathrm{N}=30.000)$. The sample of the study was composed of women who were literate, having or had active sexual life, did not have hysterectomy operation, were not menopausal, were not diagnosed with any gynecologic cancer, were not pregnant and volunteered for the study between the ages 15 and 49. In order to calculate the sample size, simple random sampling method was used. The sample was completed with $95 \%$ confidence and out of 300 subjects, at least 267 were calculated.

\section{Data collection}

For collecting the data, Individual Diagnosis Form and Health Belief Model Scale (HBMS) for Cervical Cancer and Pap Smear Test, which was prepared by a researcher, was used. After obtaining the written acknowledgement, the surveys were delivered, and returned after filling.

\section{Individual diagnosis form}

Individual diagnosis form consists of 4 sections and 43 questions. 1st Section: socio-demographic features $(\mathrm{n}=10), 2 \mathrm{nd}$ Section: cervical cancer and awareness about early diagnosis ( $n=7)$, 3rd Section: knowledge level about cervical cancer and Pap smear test $(n=11)$, 4th Section: cervical cancer risk levels $(n=15)$.

\section{HBMS for cervical cancer and pap smear test}

According to this scale, for each individual a score was obtained exactly as high as the used dimension number. An increase in scores indicates an increase in susceptibility and severity, and an increase in benefits and barriers perceived in terms of benefit perception and barrier perception. The scale was developed by Guvenc et al. in 2011, and consists of 35 items, which are collected under 5 sub-dimension. In the evaluation by the scale 5 point likert scale, the selections, "I strongly do not agree." (1), "I do not agree." (2), "I am indecisive." (3), "I agree." (4), "I strongly agree," (5) were used. Each size of scale was not combined under a total score, assessed separately (Guvenc et al., 2011).

\section{Data analysis}

The data obtained from the study were analyzed by SPSS 20 package program. After the normality test, differences among groups were analyzed; Mann Whitney U test were used for non-normally distributed variables in dual group comparison, and Bonferroni adjusted KruskalWallis $\mathrm{H}$ test were used for non-normally distributed variables in multiple group comparison. The relationships among categorical variables Chi-Square analysis were used. In intergroup difference comparison, $\mathrm{p}$ was taken as $\mathrm{p}<0.05$.

\section{Ethic consideration}

In order to conduct the study, all of the ethical committee permissions were obtained from the Yildirim Beyazit University Ataturk Education and Research Hospital, and informed consent were taken from the participants before conducting the survey. Before using the HBMS for Cervical Cancer and Pap Smear Test, all required permissions were obtained electronically.

\section{Results}

When the descriptive findings of the participants were analyzed it was determined that the mean age was $34.1 \pm 8.1$ (min:15, max:49). When the marital status of the women was assessed, it was found that $93.3 \%$ of them were married, and $6.7 \%$ of them were divorced or widowed. The educational level of $42.0 \%$ of the cases was primary school, $31.7 \%$ of them were high school graduates, and $26.3 \%$ of them were at graduate or postgraduate level. It was found out that $55.7 \%$ of the women did not work, $41.0 \%$ of them worked, and $3.3 \%$ of them were retired. The income status of $5 \%$ of the women was "middle", $20.7 \%$ of them was "good", and $24.3 \%$ of them was "poor".

When obstetrical and medical features of women were evaluated, it was learned that $77.3 \%$ of them had experienced their first sexual contact at 18 years old or over, $22.7 \%$ of them experienced it before 18 years old; and $70 \%$ of women stated that they had their first parity at 25 years old or over and $30 \%$ indicated that they had 
it before 25 years old; and $61 \%$ of women indicated that they had 1-2 parity; and $83 \%$ of them reported that they do not have any chronic disease.

When the behaviors of women about cervical cancer and Pap smear test were analyzed, it was observed that $75 \%$ of the women heard about smear test before, $74.9 \%$ of them was willing to get information about early diagnosis of cervical cancer, $48.7 \%$ of them had Pap smear test before, and $51.4 \%$ of them had been having Pap smear test irregularly. $51.7 \%$ of the women, who were informed about the Pap smear test before, heard it from medical personnel; $20 \%$ of the women took the test before for regular health check, and $24 \%$ of them took the test based on the suggestion of a doctor. When the reasons for not taking the test were considered, having no complaint $(28.3 \%)$, and lack of knowledge about the subject were the two leading reasons.

When the cervical risk factors of the women who participated in the study were evaluated, it was found out that $50.7 \%$ of the women was passive smoking, $19.7 \%$ of them was regular smoker; $8.7 \%$ of them was using oral contraceptive pills more than 5 years, $7.3 \%$ of them had abnormal smear story, $27.3 \%$ of them had irregular periods, $49 \%$ of them did not change their pad every 2-3 hours, $15 \%$ of them had spotting after intercourse and dyspareunia, $22.7 \%$ of them had their first sexual experience at or before $18,24.3 \%$ of them gave their first birth before they were $20,75 \%$ of them did not use condom during intercourse, $4.3 \%$ of them had multiple sexual partners, $10.7 \%$ of them gave birth more than 3 times, $3 \%$ of them had history of sexually transmitted diseases (STD), $19.3 \%$ of them have a diet low in fruits and vegetables, $15.7 \%$ of them had familial history of gynecological cancer (mother, aunts).

As it is set in Table 1, there is a statistically significant relation among women's age, education level, employment status, number of pregnancy and having Pap smear behavior/situation $(\mathrm{p}<0.05)$. In advanced age groups, it was clear that as education level improved, having Pap smear ratio increases in employed and retired women. The Pap smear taking ratio of women who never got pregnant was lower than that of the others $(\mathrm{p}<0.05)$. There was no statistically significant relation between marital status, income level of women and their Pap smear taking behavior $(\mathrm{p}>0.05)$.

When women's knowledge about cervical cancer and Pap smear test was considered, $8.3 \%$ of the women answered the questions wrongly, $49.9 \%$ of them answered five and more questions correctly. Hereunder, while $72.3 \%$ of the women knew that Pap smear test was a necessity in order to avoid cervical cancer and $67.3 \%$ of them knew that cervical cancer is diagnosed by Pap smear test, $68 \%$ of them did not know that human papilloma virus (HPV) vaccines protect women from cervical cancer, and $61 \%$ of them did not know that HPV is a sexually transmitted disease (Table 2).

It was found out that the mean scores of women's at sub-dimensions of HBMS for Cervical Cancer and

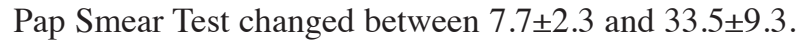
When the sub-dimension scores from HBMS of women considered, it was determined that while the benefit perception of HBMS was high, susceptibility and health motivation perceptions of them were low (Table 3).

The variables like women's age, education level,

Table 1. Women's Pap Smear Taking Situation According to their Socio-Demographic Characteristics

\begin{tabular}{|c|c|c|c|c|c|c|c|c|c|}
\hline \multirow[t]{3}{*}{ Characteristic } & & \multicolumn{6}{|c|}{ Pap smear taking situation } & \multicolumn{2}{|c|}{ Chi-Square Analysis } \\
\hline & & \multicolumn{2}{|c|}{ Yes } & \multicolumn{2}{|c|}{ No } & \multicolumn{2}{|c|}{ Total } & \multirow[b]{2}{*}{ Chi-Square } & \multirow[b]{2}{*}{$\mathrm{p}$} \\
\hline & & $\mathrm{N}$ & $\%$ & $\mathrm{~N}$ & $\%$ & $\mathrm{~N}$ & $\%$ & & \\
\hline \multirow[t]{7}{*}{ Age } & $15-19$ & 1 & 16.7 & 5 & 83.3 & 6 & 100 & 31.3 & $0,001 *$ \\
\hline & $20-24$ & 8 & 19.5 & 33 & 80.5 & 41 & 100 & & \\
\hline & $25-29$ & 26 & 51.0 & 25 & 49.0 & 51 & 100 & & \\
\hline & $30-34$ & 22 & 36.7 & 38 & 63.3 & 60 & 100 & & \\
\hline & $35-39$ & 33 & 64.7 & 18 & 35.3 & 51 & 100 & & \\
\hline & $40-44$ & 34 & 60.7 & 22 & 39.3 & 56 & 100 & & \\
\hline & $45-49$ & 22 & 62.9 & 13 & 37.1 & 35 & 100 & & \\
\hline \multirow[t]{2}{*}{ Marital Status } & Married & 136 & 48.6 & 144 & 51.4 & 280 & 100 & 0.86 & 0.712 \\
\hline & Divorced-widow & 10 & 50.0 & 10 & 50.0 & 20 & 100 & & \\
\hline \multirow[t]{3}{*}{ Education Level } & Primary School & 46 & 36.5 & 80 & 63.5 & 126 & 100 & 16.8 & $0.001 *$ \\
\hline & High School & 48 & 50.5 & 47 & 49.5 & 95 & 100 & & \\
\hline & $\geq$ Graduate & 52 & 65.8 & 27 & 34.2 & 79 & 100 & & \\
\hline \multirow[t]{3}{*}{ Employment Status } & Unemployed & 65 & 38.9 & 102 & 61.1 & 167 & 100 & 17.9 & $0.001 *$ \\
\hline & Employed & 72 & 58.5 & 51 & 41.5 & 123 & 100 & & \\
\hline & Retired & 9 & 90.0 & 1 & 10.0 & 10 & 100 & & \\
\hline \multirow[t]{10}{*}{ Income Status } & Good & 32 & 51.6 & 30 & 48.4 & 62 & 100 & 0.968 & 0.616 \\
\hline & Middle & 82 & 49.7 & 83 & 50.3 & 165 & 100 & & \\
\hline & Bad & 32 & 43.8 & 41 & 56.2 & 73 & 100 & & \\
\hline & No pregnancy & 8 & 27.6 & 21 & 72.4 & 29 & 100 & 15.13 & $0,011 *$ \\
\hline & 1 Pregnancy & 30 & 40.0 & 45 & 60.0 & 75 & 100 & & \\
\hline & 2 Pregnancy & 66 & 61.1 & 42 & 38.9 & 108 & 100 & & \\
\hline & 3 Pregnancy & 29 & 50.9 & 28 & 49.1 & 57 & 100 & & \\
\hline & 4 Pregnancy & 8 & 40.1 & 12 & 60.0 & 20 & 100 & & \\
\hline & $\geq 5$ Pregnancy & 5 & 45.5 & 6 & 54.5 & 11 & 100 & & \\
\hline & Total & 146 & 48.7 & 154 & 51.3 & 300 & 100 & & \\
\hline
\end{tabular}


Table 2. The Distribution of Women's Knowledge about Cervical Cancer and Pap Smear Test

\begin{tabular}{|c|c|c|}
\hline \multicolumn{2}{|l|}{ Cervical Cancer and Pap Smear Test Knowledge Status } & \multirow{2}{*}{$\frac{\%}{67.3}$} \\
\hline Cervical cancer is diagnosed by Pap smear test. & Yes & \\
\hline & No & 3.7 \\
\hline & Don't know & 29.0 \\
\hline \multirow[t]{3}{*}{ Regular Pap smear test taking is necessity to be protected from cervical cancer. } & Yes & 72.3 \\
\hline & No & 3.3 \\
\hline & Don't know & 24.3 \\
\hline \multirow[t]{3}{*}{ Smoking eases cervical cancer development. } & Yes & 52.0 \\
\hline & No & 10.7 \\
\hline & Don’t know & 37.3 \\
\hline \multirow[t]{3}{*}{ Women have cervical cancer only in menopause. } & Yes & 3.0 \\
\hline & No & 55.7 \\
\hline & Don't know & 41.3 \\
\hline \multirow[t]{3}{*}{ Having more than one sexual partner is a risk factor for cervical cancer. } & Yes & 34.7 \\
\hline & No & 11.7 \\
\hline & Don’t know & 53.7 \\
\hline \multirow[t]{3}{*}{ First sexual experience in early ages ( 18 and lower) is a risk factor for cervical cancer. } & Yes & 22.0 \\
\hline & No & 13.0 \\
\hline & Don't know & 65.0 \\
\hline \multirow[t]{3}{*}{ HPV vaccine is a protective vaccine against cervical cancer. } & Yes & 25.7 \\
\hline & No & 6.3 \\
\hline & Don't know & 68.0 \\
\hline \multirow[t]{3}{*}{ Before taking the Pap smear test, inside of vagina should be cleaned. } & Yes & 22.0 \\
\hline & No & 28.7 \\
\hline & Don't know & 49.3 \\
\hline
\end{tabular}

*HPV, Human Papilloma Virus

Table 3. The Distribution of Women's HBMS for Cervical Cancer and Pap Smear Test Sub-dimension Mean Scores

\begin{tabular}{llrrr}
\hline Item Number & $\begin{array}{l}\text { HBMS Sub- } \\
\text { dimensions }\end{array}$ & Mean \pm SD & Min & Max \\
\hline 3 items & Susceptibility & $7.7 \pm 2.3$ & 3.0 & 15.0 \\
7 items & Severity & $23.5 \pm 6.2$ & 7.0 & 35.0 \\
14 items & Barriers & $32.0 \pm 5.8$ & 8.0 & 40.0 \\
3 items & Health Motivation & $10.1 \pm 2.6$ & 3.0 & 15.0 \\
8 items & Benefits & $33.5 \pm 9.3$ & 14.0 & 65.0 \\
\hline *HBMS, Health Belief Model Scale & & &
\end{tabular}

marital status, employment status, income status, number of pregnancy and parity, chronic disease status, knowledge about Pap smear test, having Pap smear test / frequency-quality of the test taking, familial cancer history have effect on cervical cancer and Pap smear test sub-dimensions, cervical cancer risk scores, cervical cancer and Pap smear test knowledge score distribution $(p<0.05)$. Accordingly, it was confirmed that the risk scores of women in advanced ages were higher than those of the other age ranges. It was stated that the knowledge level of women in the age range of 35-39 was higher than that of younger women. The HBMS benefit perceptions of the ages 15-19 were significantly lower than the other age ranges. A statistically significant difference was determined between women's marital status and cervical cancer risk scores $(\mathrm{p}<0.05)$. The cervical cancer risk scores of divorced/widow women were higher than those of the married ones.

There was a statistically significant difference between women's education level and cervical cancer and Pap smear test knowledge scores, cervical cancer risk scores, mean scores of HBMS benefit/health motivation and barrier perception $(\mathrm{p}<0.05)$. As the education level of the participant women increased, the cervical cancer and Pap smear test knowledge scores increased and cervical cancer risk score decreased. In accordance with education level of the women's mean scores of HBMS, benefit and health motivation perception increased, and mean score of HBMS barrier perception decreased. There was a statistically significant difference between women's employment status and cervical cancer and Pap smear test knowledge scores, cervical cancer risk scores, mean scores of HBMS barrier perception ( $\mathrm{p}<0.05)$. Unemployed women's cervical cancer and Pap smear test knowledge scores and HBMS motivation perception mean scores were lower than those of the ones of employed ones, and barrier perception scores found out higher than the others.

There was a statistically significant difference between women's income status and cervical cancer and Pap smear test knowledge scores, cervical cancer risk scores, HBMS severity and barrier perception scores $(\mathrm{p}<0.05)$. As income status of women gets better, the cervical cancer and Pap smear test knowledge scores gets higher; as women's monthly income decreases, cervical cancer risk, HBMS severity and barrier perception score increases.

There was a statistically significant difference between the number of women's pregnancy and labor and cervical cancer risk scores $(\mathrm{p}<0.05)$. As the number of pregnancy and labor increases, cervical cancer risk increases too. The women whose pregnancy number is 5 or greater and labor number is 4 and greater have a higher cervical cancer risk level in comparison with the other women.

There was a statistically significant difference between having chronic disease and cervical cancer risk scores $(p<0.05)$. The cervical cancer risk scores of women who had chronic disease were higher than those of the others. The cervical cancer and Pap smear test knowledge scores, HBMS susceptibility and severity perception scores of 
women with a chronic disease were higher than those of the others, but this difference was not statistically significant $(\mathrm{p}>0.05)$.

There was a statistically significant difference between having knowledge about Pap smear test and cervical cancer and Pap smear test knowledge score, cervical cancer risk scores, HBMS benefit, health motivation and barrier perception scores $(\mathrm{p}<0.05)$. Pap smear test knowledge scores, HBMS benefit and health motivation perception scores of women who heard about Pap smear test before were higher than those of the ones who have not heard of it. HBMS obstacle barrier perception and cervical cancer risk scores of the women who did not hear of Pap smear test were higher than those of the ones who heard about it.

There was a statistically significant difference between women's willing to be trained for cervical cancer early diagnosis and mean score of HBMS susceptibility perception $(\mathrm{p}<0.05)$. The HBMS susceptibility perception scores of the women, who were willing to be trained about cervical cancer early diagnosis, were higher than those of the ones who were not willing to.

There was a statistically significant difference between Pap smear test taking status and Pap smear test knowledge scores, HBMS barrier, benefit and health motivation perception scores $(p<0.05)$. Cervical cancer and Pap smear test knowledge scores, HBMS benefit and health motivation perception score averages of women who took Pap smear test before were higher than those of the women who did not take the test before. HBMS barrier perception of the women who took Pap smear test before was significantly higher than that of the women who never took the test before.

There was a statistically significant difference between the frequency of Pap smear test taking and HBMS health motivation perception score averages $(\mathrm{p}<0.05)$. HBMS health motivation perception score average of the women who had the Pap smear test every year was higher than that of the women who had the test irregularly.

There was a statistically significant difference between Pap smear test quality and cervical cancer risk and HBMS susceptibility perception score averages $(\mathrm{p}<0.05)$. Cervical cancer risk and HBMS susceptibility perception score average of the women who had non-normal Pap smear samples were higher in comparison with the others.

There was a statistically significant difference between the presence of familial history of gynecological cancer and cervical cancer risk scores, cervical cancer and Pap smear test knowledge scores, and HBMS barrier perception score averages $(\mathrm{p}<0.05)$. Cervical cancer risk and cervical cancer and Pap smear test knowledge scores of the women who had a gynecological cancer history in the family was higher than those of the ones who did not have cancer in their family. HBMS barrier perception scores of the women who had gynecological cancer story in the family were higher in comparison with the others.

\section{Discussion}

The most frequent gynecological cancer type is cervical cancer which originates at cervix. The frequency of cervical cancer changes upon the country and the development of the socioeconomic conditions of that country (Ertem, 2010). Early diagnosis approach in cervical cancer achieves success and has an important place on the treatment of the cancer. Pap smear test is a cheap and safe method to prevent deaths from cervical cancer by diagnosing localized or pre-metastases cervical cancer (Gumus and Cam, 2011). However, the literature shows that Turkish women do not have protection from cancer, cervical cancer risks, scanning attitudes, and early diagnosis; and treatment ratio is also lower in Turkey than it is in the developed western countries (Ak et al., 2010; Gucuk et al., 2011). To determine the knowledge, information, attitude of women and to state affecting factors is irreplaceably valuable in protection from cancer (Hislop et al., 2004).

In our study, when the distribution of hearing about Pap smear test was analyzed, it was observed that most of the women (75\%) did not hear about Pap smear test before. According to the studies which were done on women who lived in different regions of Turkey, the ratio of hearing about Pap smear test differs. In the study by Akyuz et al. (2006) with 265 women, the ratio was $76.92 \%$, in the study by Duran (2011) with 11 women who were married the ratio was $54.5 \%$, in the study by Karaca et al. (2008) the ratio was $29.9 \%$, in the study by Demirtas and Acikgoz (2013) the ratio was $77.7 \%$, in the study by Pinar et al. (2009) with university students the ratio was $56.6 \%$, and in the study by Ak et al. (2010) the ratio was $46.8 \%$.

When the studies conducted abroad were reviewed, the ratio of hearing about Pap smear test in the study by Eke et al. (2010) in Nigeria was parallel to ours (71.5\%). In the study of Mbamara et al. (2011) in Nigeria it is determined that $85 \%$ of the women have not had the Pap smear scanning test since they have never heard of it. When the sources of hearing about Pap smear test from was observed, $51.7 \%$ of the women claimed that they heard from health personnel, $18.7 \%$ of them heard from media, $15.7 \%$ of them heard from friends-neighbors, $6.3 \%$ of them read in the internet, and $2.3 \%$ of them heard from conference-seminars. Lam et al. (2003) found that Vietnamese women living in America heard of Pap smear test mostly from health personnel. Al-Darwish et al. (2014) found that a survey at a medical school in Saudi Arabia, the main source of information was self-learning followed by medical school curriculum, faculty, hospital and Internet. In our study, in line with the literature, the main source of information about cervical cancer and protection ways from it was health personnel. Health personnel were in a continuous relationship with every part of the study and it is thought that this was effective on the results primarily.

When we studied the status of Pap smear test taking, it was found that almost half of the women $(51.3 \%)$ haven't Pap smear test before. Considering the cervical cancer peaks in two different age ranges of 35-39 and 60-64 years and taking the mean age of the women in our study into account (34.1 \pm 8.1$)$, it could be stated that cervical cancer scanning is important in middle age group (Guner and Taskiran, 2007). In the studies which was done on women in different regions of Turkey, different Pap smear test taking ratios were found (Akyuz et al., 2006; Pinar et al., 
2009). The studies give rise to the thought that the ratio of having Pap smear test is low and women don't know the importance of the topic sufficiently. This situation puts forth the necessity of routine scanning programs.

When we check the Pap smear taking ratios in different studies from several countries, we see that in the study by Lee et al. (2007) in USA, including women at the age of 40 and over, the ratio was $84 \%$, in the study by Abotchie et al. (2003) in Ghana, including women at the age of $20-35$ years the ratio was $12 \%$, in the study by Gharoro and Ikeanyi (2006) in Nigeria, including health personnel the ratio was $14.1 \%$, in the study by Moreira et al. (2006) in Brazil, including women at the age of 16-23 years the ratio was $81 \%$, in the study by Hadi and Azimirad (2010) in Iran the ratio was $66 \%$, and in the study by Urasa and Darj (2011) in Tanzania with 137 nurses the ratio was $15.4 \%$. The difference among the countries might be because of the differences in scanning programs, the level of socio-economic situation and development, individual and cultural properties of women, and the importance they give to protective health services and education (Dozier and Lawrence, 2000; Basen-Engquist et al., 2003; Barry et al., 2007).

Taking risk factors into consideration is important in determination of the women group for cervical scanning, and in determination of Pap smear test-taking period. Pap smear test started to be performed after twenties in several countries in Europe. For instance; Pap smear test is performed every 3 years between the ages 25-64 in Belgium, every 3 years between the ages 20-60 in Sweden, every 3-5 years between the ages 30- 60 in Netherland, every 2-3 years between the ages 25-64 in Greece (Ozan, 2005). In accordance with National Cancer Scanning Program in Turkey the Pap smear test is performed every five years starting at the age 30 until age 65 . The women 65 years old and over whose last two tests are negative are excluded from the scanning program (Kanbur and Capik, 2011). ACS suggests the first Pap smear scan should be performed 3 years after the first intercourse at most, and should never be later than 21 years old for the sake of early diagnosis of the cervical cancer. For women over 30 years old whose last three test results are normal could increase the scanning period to three years (Ozan, 2005; Akyuz et al., 2006). However, in our study, it was seen that women could not determine when and how often they should have Pap smear scan exactly. According to this, $51.4 \%$ of women claimed that they get Pap smear scan irregularly.

In our study it was found that socio-demographic properties of women are influential on their Pap smear test taking attitude. There was a statistically significant relationship between age, education level, employment status, number of pregnancy of women and their having Pap smear test attitude $(\mathrm{p}<0.05)$. It was found that in older ages, as education level increases, having Pap smear test ratio increases in employed and retired women. It was detected that Pap smear test taking ratio of women, who did not get pregnant before, was lower in comparison with the others. Kalyoncu et al. (2003) also found that in accordance with parity number, Pap smear test taking ratio increases. In line with the results of our study, Acikgoz et al. (2011) claimed that women between 40-49 ages and Akyuz et al. (2006) states that women between 3039 ages have Pap smear test more often. Behbakht et al. (2004) found that Pap smear test taking ratio increases as education level of women increases and Lee et al. (2007) shows that Pap smear test taking ratio of employed women is higher in comparison with unemployed ones. Damiani et al. (2012) determined that among women who attended screening, those with lower levels of education and lower occupational classes were more likely than more advantaged women to attend organized screening programs rather than being screened on the basis of their own initiative.

The studies about Pap smear scanning show that women are not informed enough about the importance of the subject. Health personnel's appropriate communication with women about cervical cancer scan is a major supportive factor for women to take scanning (Farland et al., 2003; Moreira et al., 2006). According to the results of our study, $74.9 \%$ of the women claimed that they were willing to get information and be trained about early diagnosis of cervical cancer. The analysis showed that women who wanted to get informed about early diagnosis of cervical cancer has Pap smear test more often than the others. It is seen that women's seeking for information affects Pap smear test taking in a positive way.

Finding out women's having Pap smear test reasons is important in terms of having an opinion about the attention they pay to protective health behavior for early diagnosis of cervical cancer. Most of the women in our study (24\%) had Pap smear test because of doctor's request. In line with the results of our study, Shekhar et al. (2013) found that, majority of participants held a view that Pap test is doctor's procedure in India.

The most important reasons of low ratios of women taking cervical cancer scan program in literature are lack of knowledge about cervical cancer and risk factors, shyness, fear of pain or cancer, inappropriate scan schedules or lack of female doctors who perform the test, the fear of abnormal results, not being knowledgeable enough about cervical cancer scanning program, difficulty in reaching to service, insensitivity, fatalist approach and lack of any complaints (Ezem, 2007; Pinar et al., 2008; Ak et al., 2010). In our study the leading reasons for low ratios of women not having Pap smear were lack of any complaints, and lack of knowledge about this subject (time-frequencylocation) (21\%). According to the Demirtas and Acikgoz (2013) study findings, not heard about the Pap test, not know the reason for having Pap test, not feel the need, not complain of symptoms, time constraints, neglect, being young and embarrassment-hesitation-fear were among the reasons for not having had Pap test.

Studies have shown that some lifestyle, environmental factor, history of illness, history of personal health, and social psychological factors may promote develop cervical cancer (Kivistik et al., 2011; Natphopsuk et al., 2012; Demirtas and Acikgoz, 2013). In our study it was detected that women did not have information about protection from cervical cancer and risk factors of cervical cancer enough and they needed training about these topics. In a descriptive cross-sectional study, have reported the knowledge about risk factors to be less than $40 \%$ among 
medical workers that included nurses, doctors and final year medical students (Mutyaba et al., 2006). Al-Darwish et al. (2014) found that on average only $55 \%$ of the students had knowledge about the risks factors.

The factors affecting behavior and attitude of women about cervical cancer scanning are multidimensional. Individual's cultural beliefs, health / sickness perception, support of family and surrounding, knowledge about health and risk perception, the belief about the applications in early diagnosis of the disease are the main factors (Mc Donald et al., 1999). Bekar et al. (2013) found that more than half of the women think that to be protected against gynecological cancer, handling stress, avoiding diets including excessive animal fat, weight control, exercising regularly are important.

Another factor affecting women to get scanning is thought to be their health beliefs. When health beliefs about cervical cancer scanning attitudes of women obtained from Cervical Cancer and Pap Smear Test HBMS were considered, it was found that scale sub-dimension means changed between $7.7 \pm 2.3$ and 33.5 \pm 9.3 . When women's HBMS sub-dimension score averages were analyzed, although the benefit perception was high, susceptibility and health motivation perceptions were low. As education level increased, in older ages, HBMS benefit and health motivation perceptions were high in employed women and women having Pap smear test. It was stated that women, who were willing to be trained and had abnormal Pap smear result sample, had higher susceptibility perception scores in HBMS. According to the Demirtas and Acikgoz (2013) women who had obtained a Pap Smear Test had fewer perceived barriers and higher Benefits of Pap Smear Tests and Health Motivation score than those who had never obtained a Pap Smear Test. It was identified that the same study women who have not known the reason for Pap test had fewer Benefits of Pap Smear Tests and Health Motivation score and higher perceived barriers than those who have known the reason.

In conclusion, it was determined that the awareness of women about cervical cancer and Pap smear test was insufficient, and susceptibility and motivation perception towards having Pap smear test was low. In this sense, starting population-based scanning programs, arranging educative programs, training women about risk factors of cervical cancers and enabling them to participate in scanning tests is needed for early diagnosis of cervical cancer. On the other hand, studies about the reasons of women's not having Pap smear test and studies evaluating their health beliefs should be focused, and in health care facilities, appropriate environments should be provided to refer women for early diagnosis.

\section{References}

Abotchie PN, Shokar NK (2009). Cervical cancer screening among college students in Ghana: knowledge and health beliefs. Int J Gynecol Cancer, 19, 412-6.

Acikgoz A, Cehreli R, Ellidokuz H (2011). Women's knowledge and attitude about cancer and the behaviour for early diagnosis procedures. Dokuz Eylul University J Faculty Med, 25, 145-54.
Ak M, Canbal M, Turan S, et al (2010). Attitude concerning the Papsmear test of women who admitted to the family medicine out patient clinic. Konuralp J, 2, 1-4.

Akyuz A, Guvenc G, Yavan T, et al (2006). Evaluation of the Papsmear test status of women and of the factors affecting this status. Gulhane Med J, 48, 25-9.

Al-Darwish AA, Al-Naim AF, Al-Mulhim KS, et al (2014). Knowledge about cervical cancer early warning signs and symptoms, risk factors and vaccination among students at a medical school in Al-Ahsa, Kingdom of Saudi Arabia. Asian Pac J Cancer Prev, 15, 2529-32.

American Cancer Society (ACS) (2007). Cancer prevention and early detection, facts and figures, Retrieved 2014-03-28 from http://www.cancer.org/downloads/STT/Global Cancer Facts and Figures 2007 rev.pdf.

Barry HC, Smith M, Weismantel D, et al (2007). The feasibility of risk-based cervical cancer screening. Prev Med, 45, 125-9.

Basen-Engquist K, Paskett ED, Buzaglo J, et al (2003). Cervical cancer, behavioral factors related to screening, diagnosis and survivors quality of life. Cancer, 98, 2009-14.

Behbakht K, Lynch A, Teal S, et al (2004). Social and cultural barriers to papanicolaou test screening an urban population. Obstet Gynecol, 104, 1355-61.

Bekar M, Guler H, Evcili F, et al (2013). Determining the knowledge of women and their attitudes regarding gynecological cancer prevention. Asian Pac J Cancer Prev, 14, 6055-9.

Damiani G, Federico B, Basso D, et al (2012). Socioeconomic disparities in the uptake of breast and cervical cancer screening in Italy: a cross sectional study. BMC Public Health, 12, 99.

Demirtas B, Acikgoz I (2013). Promoting attendance at cervical cancer screening: understanding the relationship with turkish womens' health beliefs. Asian Pac J Cancer Prev, 14, 333-40.

Dozier KJ, Lawrence D (2000). Socio-demographic predictors of adherence to annual cervical cancer screening in minority women. Cancer Nurs, 23, 350-6.

Duran ET (2011). Examination with the health belief model of women's attitudes to cervical cancer and early diagnosis in Turkey: A qualitative study. Asian Pac J Cancer Prev, 12, 1179-84.

Eke NO, Ezeama C, Eke CO (2010). Knowledge of cervical cancer and its screening amongst female workers in Newi, Nigeria. Afrimedic J, 1, 31-6.

Ertem G (2010). Home care in gynecological cancers. Turkish J Oncol, 25, 124-32.

Ezem BU (2007). Awareness and uptake of cervical cancer screening in Owerri, South-Eastern Nigeria. Ann Afr Med, 6, 94-8.

Gharoro EP, Ikeanyi EN (2006). An appraisal of the level of awareness and utilization of the papsmear as a cervical cancers creening test among female health workers in a tertiary health institution. Int J Gynecol Cancer, 16, 1063-8.

Gucuk S, Servet A, Arica S (2011). Van mother-child health and family planning center Pap smear clinics of information, evaluation of applicants. TAF Prev Med Bull, 10, 527-32.

Gumus AB, Cam O (2011). Relationships between early diagnosis attitudes in cervical cancer of women and levels of self-esteem, body perception and hopelessness. Medicus Nobel, 7, 46-52.

Guner H, Taskiran C (2007). Epidemiology of cervical cancer and the role of human papilloma virus. Turkish J Obstet Gynecol, 4, 11-9.

Guvenc G, Akyuz A, Acikel CH (2011). Health belief model scale for cervical cancer and papsmear test: psychometric testing. J Adv Nurs, 67, 428-37. 


\section{Gokce Banu Acar and Gul Pinar}

Hadi N, Azimirad A (2010). Knowledge attitude and practice of women in Shiraz about cervical cancer and Papsmear 2009. Iranian J Cancer Prev, 3, 117-26.

Hislop TG, Teh C, Lai A, et al (2004). Pap screening and knowledge of risk factors for cervical cancer in Chinese women in British Columbia, Canada. Ethn Health, 9, 267-81.

Jemal A, Thomas A, Murray T, et al (2002). Cancer statistics. CA Cancer J Clin, 52, 23-47.

Kalyoncu C, Isikli B, Ozalp S, et al (2003). Knowledge, attitudes and behaviors about Pap smear of women who applicants department of obstetrics and gynecology Osmangazi University. Health Society, 13, 60-6.

Kanbur A, Capik C (2011). Cervical cancer prevention, early diagnosis-screening methods and midwives / nurses role. Hacettepe University Faculty of Health Sci Nurs J, 18, 61-72.

Karaca M, Palanci Y, Aksu S (2008). Pap smear how much is known, how much is being implemented? Turkiye Klinikleri J Gynecol Obst, 18, 22-8.

Kivistik A, Lang K, Baili P, Anttila A, Virus P (2011). Women's knowledge about cervical cancer risk factors, screening, and reasons for non-participation in cervical cancer screening programme in Estonia. BMC Women's Health, 11, 43.

Lam TK, McPhee SJ, Mock J, et al (2003). Encouraging Vietnamese-American women to obtain Pap test through lay health worker outreach and media education. J Gen Intern Med, 18, 516-24.

Lee-Lin F, Pett M, Menon U, et al (2007). Cervical cancer beliefs and Pap test screening practices among Chinese American immigrants. Oncol Nurs Forum, 34, 1203-9.

Mbamara SU, Ikpeze OC, Okonkwo JE, et al (2011). Knowledge, attitude and practice of cervical cancer screening among women attending gynecology clinics in a tertiary level medical care center in southeastern Nigeria. J Reprod Med, 56, 491-6.

Mc Donald PA, Thorne DD, Pearson JC, et al (1999). Perceptions and knowledge of breast cancer among African American women residing in public housing. Ethn Dis, 9, 81-93.

Mc Farland DM (2003). Cervical cancer and papsmear screening in Botswana: knowledge and perceptions. Int Nurs Rev, 50, 167-75.

Ministry of Health (2010). Health statistics annual, retrieved 2014-02-15, from http://www.saglik.gov.tr.

Moreira ED, Oliveira BG, Ferraz FM, et al (2006). Knowledge and attitudes about human papilloma virus, Pap smears, and cervical cancer among young women in Brazil: Implications for health education and prevention. Int J Gynecol Cancer, 16, 599-603.

Mutyaba T, Mmiro FA, Weiderpass E (2006). Knowledge, attitudes and practices on cervical cancer screening among the medical workers of Mulago Hospital, Uganda. BMC Med Educ, 1, 6-13.

Natphopsuk S, Settheetham-Ishida W, Sinawat S, et al (2012). Risk factors for cervical cancer in northeastern Thailand: detailed analyses of sexual and smoking behavior. Asian Pac J Cancer Prev, 13, 5489-95.

Nazlican E,Akbaba M, Koyuncu H, et al (2010). Cervical cancer screening between 35-40 aged women at Kisecik region of Hatay provinence. TAF Prev Med Bull, 9, 471-4.

Ozan H (2005). Pap Smear: When? How? Who is from?. Turkish J Obstet Gynecol, 2, 35-40.

Parkin DM, Bray F, Ferlay J, et al (2005). Global cancer statistics 2002. CA Cancer J Clin, 55, 74-108.

Pinar G, Topuz S, Dogan N, et al (2009). The knowledge and practice of girls tudents of Baskent University about cervix cancer and its prevention. Turkish J Gynaecologic Oncol, 3, 66-73.

Reis N, Beji KN, Coskun A (2010). Quality of life and sexual functioning in gynecological cancer patients: results from quantitative and qualitaty data. Eur J Oncol Nurs, 14, 137-46.

Saegrov S, Halding AG (2004). What is it like living with the diagnosis of cancer? Eur J Cancer Care, 13, 145-53.

Shekhar S, Sharma C, Thakur S, et al (2013). Cervical cancer screening: knowledge, attitude and practices among nursing staff in a tertiary level teaching institution of rural India. Asian Pac J Cancer Prev, 14, 3641-5.

Urasa M, Darj E (2011). Knowledge of cervical cancer and screening practices of nurses at a regional hospital in Tanzania. African Health Sci, 11, 48-57.

WHO, Cancer, Retrieved 2014-03-20, from http://www.who.int/ mediacentre/factsheets/fs297/en/index.html.

WHO (2006). Comprehensive cervical cancer control: a guide to essential practice, Retrieved 2014-05-15 from http://www. who.int/reproductive health/publications/cervical_cancer_ gep/text.pdf. 